\title{
Long term survival effect of metoprolol in dilated cardiomyopathy
}

\author{
A Di Lenarda, R De Maria, A Gavazzi, D Gregori, M Parolini, G Sinagra, L Salvatore, \\ F Longaro, E Bernobich, F Camerini, on behalf of the SPIC (Italian Multicentre \\ Cardiomyopathy Study) Group
}

\begin{abstract}
Objective-To evaluate the additive effect of metoprolol treatment on long term incidence of fatal and non-fatal cardiac events in idiopathic dilated cardiomyopathy.

Design-586 patients with idiopathic dilated cardiomyopathy were prospectively enrolled in a multicentre registry and followed up for a mean (SD) of 52 (32) months. Metoprolol, carefully titrated to the maximum tolerated dose, was added to conventional heart failure treatment in 175 patients.

Results-Survival and transplant-free survival at seven years were significantly higher in the 175 metoprolol treated patients than in the remaining 411 on standard treatment $(81 \% v 60 \%, \mathrm{p}<0.001$, and $69 \%$ v $49 \%, \mathrm{p}<0.001$, respectively). By multivariate analysis, metoprolol independently predicted survival and transplant-free survival (relative risk reduction values for all cause mortality and combined mortality or transplantation $51 \%(95 \%$ confidence interval $21 \%$ to $69 \%), p=0.002$, and $34 \%(5 \%$ to $53 \%)$, p $=0.01$, respectively). New York Heart Association class, left ventricular end diastolic diameter, and pulmonary wedge pressure were also predictive. Seven year survival $(80 \% \quad v \quad 62 \%, p=0.004)$ and transplant-free survival $(68 \% \quad v \quad 51 \%$, $p=0.005$ ) were significantly higher in 127 metoprolol treated cases than in 127 controls selected from the entire control cohort and appropriately matched. Metoprolol was associated with a $30 \%$ reduction in all cause mortality ( $7 \%$ to $48 \%$, $p=0.015$ ) and a $26 \%$ reduction in mortality or transplantation $(7 \%$ to $41 \%$, $\mathrm{p}=0.009$ ).

Conclusions-The addition of metoprolol to standard heart failure treatment, including angiotensin converting enzyme inhibitors, was effective in the long term, reducing both all cause mortality and transplantation in patients with idiopathic dilated cardiomyopathy.

(Heart 1998;79:337-344)
\end{abstract}

Keywords: $\beta$ blockade; dilated cardiomyopathy; heart failure

The failure of conventional treatment ${ }^{1}$ to have any important effect on the prognosis of patients with heart failure emphasises the need for new, more effective drugs for this condition.
Activation of the sympathetic nervous system is one of the cardinal pathophysiological abnormalities in patients with chronic heart failure. The degree of neurohormonal activation has prognostic importance, ${ }^{2-4}$ and neurohormonal blockade can influence both symptoms and survival in heart failure patients. ${ }^{4}$

For many years $\beta$ blockers have been contraindicated in patients with chronic heart failure, mainly because of their adverse short term effects. ${ }^{5}$ However, many small controlled and uncontrolled clinical trials since the 1970s have shown beneficial effects on symptoms and on left ventricular function in patients with heart failure, particularly in cases of idiopathic aetiology. ${ }^{6-9}$ Two multicentre studies with the $\beta_{1}$ selective agents metoprolol ${ }^{10}$ and bisoprolol ${ }^{11}$ suggested a positive effect of $\beta$ blockers on progressive functional deterioration in dilated cardiomyopathy. The non-selective vasodilating $\beta$ blocker carvedilol significantly reduced mortality and hospital admission rates for cardiovascular causes ${ }^{12}$ in heart failure of both ischaemic and non-ischaemic aetiology. However, these trials were criticised as being inadequate to identify a survival effect because of sample size ${ }^{10}$ paucity of events, ${ }^{12}$ or relative brevity of follow up. ${ }^{10-12}$ Currently, controlled long term data on $\beta$ blocker treatment in heart failure are lacking.

In this report we analyse the long term effect of metoprolol as an adjunct to conventional treatment for heart failure on all cause mortality and combined mortality or transplantation in a cohort of patients with idiopathic dilated cardiomyopathy.

\section{Methods}

STUDY POPULATION

Between January 1986 and February 1996, 586 consecutive patients with idiopathic dilated cardiomyopathy from 14 centres $^{13}$ were prospectively enrolled in a multicentre registry, designed to investigate the natural history of the disease with particular emphasis on its early stages. Entry and study criteria have already been published in detail. ${ }^{14}$ Briefly, patients were referred to the participating centres because of heart failure, high grade ventricular arrhythmias, depression of left ventricular function of unknown cause, or any combination of these criteria. The clinical suspicion of idiopathic dilated cardiomyopathy was confirmed invasively in every patient by the demonstration of: (1) absence of significant coronary artery disease (more than 50\% luminal diameter reduction of a major coronary artery branch), as determined by coronary angiography; 
(2) exclusion by endomyocardial biopsy of specific heart muscle disease or active myocarditis, diagnosed in accordance with Dallas criteria $^{15}$; and (3) a left ventricular ejection fraction less than 0.50 , as evaluated by ventricular cineangiography, radionuclide angiography, or echocardiography.

\section{TREATMENT}

Patients were treated with optimal conventional treatment for heart failure or left ventricular dysfunction, on the basis of clinical judgement.

Treatment included angiotensin converting enzyme (ACE) inhibitors in 86\%, mainly captopril ( $\mathrm{n}=229$, average (SD) daily dose 72 (40) $\mathrm{mg}$ ), enalapril $(\mathrm{n}=225$, average daily dose 17 (11) mg), and lisinopril ( $\mathrm{n}=32$, average daily dose $13(10) \mathrm{mg}$ ), and digitalis in $79 \%$ of patients. Diuretics, usually frusemide $(\mathrm{n}=286)$ at an average daily dose of 41 (36) $\mathrm{mg}$, were also used to relieve congestive symptoms. Low dose amiodarone ( $\mathrm{n}=204$, average daily dose 226 (47) $\mathrm{mg}$ ) was used when indicated for complex symptomatic ventricular arrhythmias or control of heart rate in atrial fibrillation.

One hundred and seventy five patients showing either substantial left ventricular dysfunction, as expressed by a left ventricular ejection fraction of less than 0.40 , or a history of symptomatic heart failure, or both, were treated from enrolment onwards with metoprolol, after optimal stabilisation on conventional medical treatment. Patients received a test dose of metoprolol ( $5 \mathrm{mg}$ twice daily for two to seven days), followed by a titration period consisting of a stepwise increase in dosage over seven weeks, as follows: week $1,5 \mathrm{mg}$ twice daily; week $2,5 \mathrm{mg}$ three times daily; week 3, $10 \mathrm{mg}$ three times daily; week 4, $25 \mathrm{mg}$ twice daily; week $5,25 \mathrm{mg}$ three times daily; week $6,50 \mathrm{mg}$ twice daily; week 7 and onwards, $50 \mathrm{mg}$ three times daily, until achievement of a resting heart rate of 60 (10) beats $/ \mathrm{min}$. Metoprolol dose was increased to $>150 \mathrm{mg} /$ day if heart rate was persistently higher than the quoted target in the absence of worsening heart failure.

Follow up data were obtained from regular follow up visits at each institution or by telephone contact with patients or their physician.

END POINTS

The primary end point was all cause mortality. Death was classified as (1) due to progressive heart failure; (2) due to embolism; (3) sudden and unexpected, when it occurred within one hour of new symptoms or during sleep in patients in New York Heart Association (NYHA) class I to III; (4) due to unspecified cause, when the mechanism could not be established with certainty; and (5) non-cardiac. Secondary end points were all cause mortality or heart transplantation. Heart transplantation was indicated when hospital admission - with or without intravenous inotropic support-was required because of refractory heart failure or in the presence of a peak oxygen consumption less than $14 \mathrm{ml} / \mathrm{kg} / \mathrm{min}$.

The effect of metoprolol on the combined risk of death or transplantation was evaluated with the use of a time to first event analysis.

The study was considered closed on 28 February 1997 . No patient was lost to follow up.

STATISTICAL ANALYSIS

The study was organised as an observational cohort investigation that aimed to identify the clinical and instrumental variables related to prognosis in the population of our registry. Missing values ranged from $1 \%$ to $15 \%$ according to the variable selected, and were not imputed to avoid bias. Metoprolol treated cases were compared with patients on conventional treatment alone using unpaired Student's $t$ test for continuous variables and $\chi^{2}$ test with Yates correction for categorical variables. Since baseline clinical or laboratory differences between treated and untreated patients might affect prognosis, we maximised the chances of detecting such differences by omitting to correct for multiple comparisons. A two sided $\mathrm{p}$ value of $<0.05$ was accepted as indicating statistical significance.

Survival curves were estimated with the Kaplan-Meier estimator, and differences between curves for treated and untreated patients were first assessed by log-rank test. Prognostic variables for primary and secondary end points in the whole population were identified by a Cox proportional hazard model.

After performing our first analysis on the whole population, we realised that the characteristics of metoprolol treated patients differed somewhat at the time of enrolment from those of patients on conventional treatment alone. To reduce potential selection biases that might derive from differences in severity of disease at baseline, and to allow a more meaningful comparison between treated and untreated patients, we performed individual one to one matching for key prognostic variables.

Patients were matched on the basis of the following variables:

(1) Those that are commonly used to stratify populations (sex, age, calendar period of enrolment).

(2) Those that predicted prognosis in published reports, ${ }^{2} 1617$ such as NYHA class (I-II $v$ III-IV) and left ventricular ejection fraction (separated into two groups, $\leqslant 0.25$ and $>0.25$, and in any case within a 10 unit difference).

(3) Those that predicted prognosis in the present series (see table 3), such as left ventricular end diastolic diameter $\left(\leqslant 36 \mathrm{~mm}^{2}\right.$ and $>36 \mathrm{~mm}^{2}$ ) and pulmonary wedge pressure $(\leqslant 15 \mathrm{~mm} \mathrm{Hg}$ and $>15 \mathrm{~mm} \mathrm{Hg}$ ).

(4) Those that differed between the two populations, such as cardiac index $\left(<31 / \mathrm{min} / \mathrm{m}^{2}\right.$ and $\geqslant 31 / \mathrm{min} / \mathrm{m}^{2}$ ).

(5) Those considered of clinical relevance, such as a duration of symptoms $\leqslant 6$ months and $>6$ months.

For each case in the metoprolol cohort, matching controls in the conventional treatment 
Table 1 Baseline characteristics in metoprolol treated cases and in controls on conventional heart failure treatment; data in unmatched and matched cohorts

\begin{tabular}{|c|c|c|c|c|c|c|c|c|c|c|}
\hline \multirow[b]{2}{*}{ (A) Number (\%) of cases } & \multicolumn{2}{|c|}{$\begin{array}{l}\text { Entire control cohort } \\
(n=411)\end{array}$} & \multirow{2}{*}{$p$ value } & \multicolumn{2}{|c|}{$\begin{array}{l}\text { Metoprolol cases } \\
(n=175)\end{array}$} & \multicolumn{2}{|c|}{$\begin{array}{l}\text { Matched controls } \\
(n=127)\end{array}$} & \multirow[t]{2}{*}{$p$ value } & \multicolumn{2}{|c|}{$\begin{array}{l}\text { Matched metoprolol cases } \\
(n=127)\end{array}$} \\
\hline & & & & & & & & & & \\
\hline Male sex & 306 & $(75)$ & & 129 & $(74)$ & 94 & $(75)$ & NS & 94 & $(75)$ \\
\hline NYHA class I & 79 & (19) & & 39 & (22) & 25 & (20) & & 34 & (27) \\
\hline NYHA class II & 180 & $(44)$ & & 83 & $(47)$ & 70 & (55) & & 61 & (48) \\
\hline NYHA class III & 119 & (29) & & 46 & (26) & 27 & (21) & & 27 & (21) \\
\hline NYHA class IV & 33 & $(8)$ & NS & 7 & $(4)$ & 5 & $(4)$ & & 5 & $(4)$ \\
\hline Borderline hypertension & 55 & (14) & 0.004 & 41 & $(24)$ & 20 & $(16)$ & NS & 32 & $(26)$ \\
\hline Atrial fibrillation & 46 & (11) & 0.009 & 7 & (4) & 10 & $(8)$ & NS & 3 & (2) \\
\hline First degree AV block & 25 & $(8)$ & NS & 20 & (12) & 5 & (5) & NS & 15 & (12) \\
\hline Left bundle branch block & 140 & (37) & NS & 56 & (33) & 46 & (40) & NS & 42 & (34) \\
\hline Digitalis & 310 & $(75)$ & 0.003 & 152 & (87) & 93 & (73) & 0.01 & 110 & (87) \\
\hline ACE inhibitors & 337 & (82) & 0.00001 & 166 & (95) & 114 & (90) & NS & 120 & (94) \\
\hline Frusemide & 216 & (53) & 0.007 & 70 & $(40)$ & 71 & (56) & 0.01 & 50 & (39) \\
\hline Amiodarone & 164 & $(40)$ & 0.0001 & 40 & (23) & 47 & $(37)$ & 0.01 & 28 & $(22)$ \\
\hline \multicolumn{11}{|l|}{ (B) Mean (SD) values } \\
\hline Age (years) & 44 & (12) & NS & 43 & (13) & 43 & (12) & NS & 43 & (13) \\
\hline Duration of disease (months) & 25 & (39) & NS & 29 & $(42)$ & 25 & (37) & NS & 31 & (42) \\
\hline \multicolumn{11}{|l|}{ Duration of amiodarone treatment } \\
\hline (months) & 19 & $(22)$ & NS & 21 & $(22)$ & 26 & $(25)$ & NS & 18 & $(20)$ \\
\hline Heart rate (beats/min) & 83 & (17) & NS & 82 & (16) & 82 & (14) & NS & 81 & (15) \\
\hline Systolic blood pressure (mm Hg) & 121 & $(15)$ & NS & 120 & (13) & 120 & $(14)$ & NS & 120 & (12) \\
\hline Diastolic blood pressure $(\mathrm{mm} \mathrm{Hg})$ & 78 & (10) & NS & 78 & (9) & 78 & (9) & NS & 78 & $(8)$ \\
\hline VPBs/hour & 114 & $(223)$ & NS & 83 & $(166)$ & 95 & $(183)$ & NS & 74 & $(148)$ \\
\hline VC/hour & 1.97 & $(7.6)$ & NS & 1.76 & $(5.6)$ & 1.78 & $(6.0)$ & NS & 1.45 & $(5.0)$ \\
\hline VT episodes/hour & 0.12 & $(0.104)$ & NS & 0.11 & $(0.29)$ & 0.11 & $(0.51)$ & NS & 0.08 & $(0.15)$ \\
\hline $\mathrm{LV}$ end diastolic diameter $\left(\mathrm{mm} / \mathrm{m}^{2}\right)$ & 39 & (6) & NS & 38 & $(6)$ & 39 & $(6)$ & NS & 38 & $(5)$ \\
\hline LV ejection fraction & 0.28 & $(0.09)$ & NS & 0.28 & $(0.09)$ & 0.29 & $(0.09)$ & NS & 0.29 & $(0.09)$ \\
\hline Pulmonary artery pressure $(\mathrm{mm} \mathrm{Hg})$ & 22 & $(11)$ & NS & 20 & $(9)$ & 20 & $(9)$ & NS & 19 & $(9)$ \\
\hline Wedge pressure $(\mathrm{mm} \mathrm{Hg})$ & 15 & (9) & 0.012 & 13 & (8) & 13 & (8) & NS & 12 & (8) \\
\hline Mean aortic pressure $(\mathrm{mm} \mathrm{Hg})$ & 89 & (15) & 0.016 & 86 & (12) & 90 & (16) & NS & 87 & (12) \\
\hline Cardiac index $\left(1 / \mathrm{min} / \mathrm{m}^{2}\right)$ & 2.98 & $(0.99)$ & 0.0001 & 3.78 & $(1.11)$ & 3.56 & $(1.1)$ & 0.0001 & 3.95 & $(1.4)$ \\
\hline
\end{tabular}

$\mathrm{AV}$, atrioventricular; ACE, angiotensin converting enzyme; LV, left ventricular; NYHA, New York Heart Association; VC, ventricular couplets; VPB, ventricular premature beats; VT, ventricular tachycardia.

cohort were identified and then selected randomly for the construction of the one to one matched cohort.

Differences between groups were assessed by paired Student's $t$ test for continuous variables and by $\chi^{2}$ test with Yates correction for categorical variables. A proportional hazard model was chosen for the analysis of the cohort data. As a result of the matching procedure, patients belonging to the subcohorts were no longer independent, so a paired conditional analysis was required; the variables used to match the two groups (see above) were not included in the model.

To evaluate the effect of treatment on mode of death after adjustment for potential confounding effects, we estimated a Cox type regression bivariate proportional hazards model for competing risk. The model defines event specific covariates ${ }^{18}$ and was selected by means of a forward procedure. For each model, comparison in goodness of fit was in the form of a score test.

All analyses were performed in Splus $3.3^{18 a}$ using the libraries of Lafterty and Therneau (1993). ${ }^{18 b}$

\section{Results}

COMPARISON OF ENTIRE CONTROL AND

METOPROLOL COHORTS

Five hundred and eighty six consecutive patients were enrolled in our registry between January 1986 and February 1996.

One hundred and seventy five of these patients $(29.8 \%$ of the whole population, $94 \%$ of whom came from a single centre) were treated from enrolment onwards with metoprolol. The group included four $(2.3 \%)$ who did not tolerate the test dose of metoprolol for worsening heart failure; one of them tolerated metoprolol at a second attempt and could be titrated to $20 \mathrm{mg} /$ day. After titration to the maximum tolerated levels, the average (SD) daily dose was 117 (46) mg (range 20 to 200, excluding the three intolerant patients); 74 patients $(42 \%)$ were receiving $\leqslant 100 \mathrm{mg}$ daily (mean dose 70 (26) $\mathrm{mg}$ ), and 98 (57\%) $>100 \mathrm{mg}$ daily (mean dose 153 (14) mg); eight patients in the latter group $(4.5 \%)$ received a final daily dose $>150 \mathrm{mg}$ (range 175 to $200 \mathrm{mg}$ ). Metoprolol treatment was continued until the end of follow up in all but seven patients $(5 \%)$. These seven patients were withdrawn from $\beta$ blockade because of refractory heart failure requiring inotropic support before death or transplantation.

The entire conventional treatment cohort consisted of 411 subjects and included all patients $(\mathrm{n}=75)$ who started metoprolol treatment at any time after enrolment (intention to treat analysis).

Table 1 (A and B) shows the clinical and laboratory characteristics at enrolment in the two groups of patients. The study cohort of 175 patients treated with metoprolol had a lower prevalence of atrial fibrillation, lower mean aortic and filling pressures, a higher frequency of borderline hypertension, and a higher cardiac index. They were more often treated with digitalis and ACE inhibitors and less often with frusemide and amiodarone.

During a mean follow up of 52 (32) months (range $<1$ to 147$), 145$ of 586 patients $(24.7 \%$ ) reached a primary end point, mostly cardiovascular death (132 cases, 91\%) (table 2). Cardiovascular deaths were due to refractory heart 
Table 2 Outcome in unmatched and matched cohorts

\begin{tabular}{|c|c|c|c|c|c|c|c|c|}
\hline & \multicolumn{2}{|c|}{$\begin{array}{l}\text { Entire control cohort } \\
(n=411)\end{array}$} & \multicolumn{2}{|c|}{$\begin{array}{l}\text { Metoprolol cases } \\
(n=175)\end{array}$} & \multicolumn{2}{|c|}{$\begin{array}{l}\text { Matched controls } \\
(n=127)\end{array}$} & \multicolumn{2}{|c|}{$\begin{array}{l}\text { Matched metoprolol } \\
\text { cases }(n=127)\end{array}$} \\
\hline & $n$ & $\%$ & $n$ & $\%$ & $n$ & $\%$ & $n$ & $\%$ \\
\hline \multicolumn{9}{|l|}{ Deaths } \\
\hline Secondary to heart failure & 42 & 10 & 7 & 4 & 11 & 9 & 3 & 2 \\
\hline Sudden & 59 & 14 & 12 & 7 & 24 & 19 & 11 & 9 \\
\hline Embolism & 2 & 1 & 0 & 0 & 1 & 1 & 0 & 0 \\
\hline Non-cardiac cause & 9 & 2 & 4 & 2 & 2 & 1 & 3 & 2 \\
\hline Unspecified cause & 10 & 2 & 0 & 0 & 0 & 0 & 0 & 0 \\
\hline Heart transplants & 54 & 13 & 18 & 10 & 16 & 13 & 12 & 10 \\
\hline Mean (SD) follow up (months) & \multicolumn{2}{|c|}{$54(33)$} & \multicolumn{2}{|c|}{$50(29)$} & \multicolumn{2}{|c|}{$55(34)$} & \multicolumn{2}{|c|}{$53(29)$} \\
\hline
\end{tabular}

failure in 49 cases $(37 \%)$, sudden death in 71 $(54 \%)$, embolism in two $(1.5 \%)$, and to an unspecified mechanism in $10(7.5 \%)$. Seventy two patients underwent heart transplantation (37\% of total end points).

Metoprolol treated patients had significantly higher survival rates than the entire control
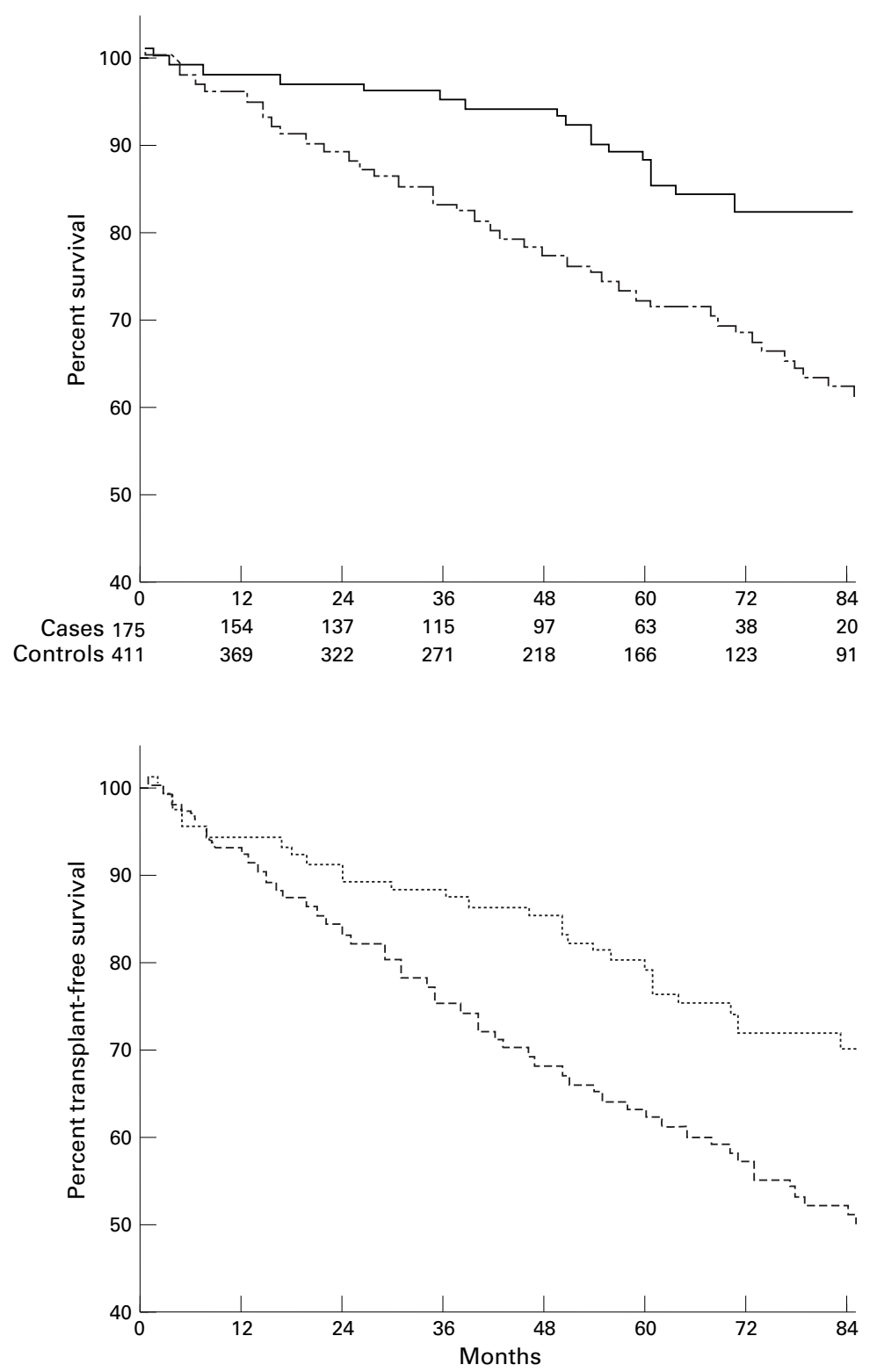

Figure 1 Survival (upper panel) and transplant-free survival (lower panel) in metoprolol treated cases (solid line) and entire control cohort (hatched line). Numbers below the $X$ axis represent patients remaining at risk at each time interval considered. cohort at two years $(96 \%$ v $87 \%, \mathrm{p}=0.003)$, five years $(87 \% v 70 \%, \mathrm{p}<0.001)$, and seven years $(81 \%$ v 60\%, p < 0.001). The curves were superimposed during the first six months after enrolment, and progressively divergent thereafter (fig 1, upper panel). Transplant-free survival rates were also higher in metoprolol treated patients than in the entire control cohort at two years $(88 \% v 81 \%, \mathrm{p}=0.06)$, five years $(75 \%$ v $61 \%, \mathrm{p}=0.001)$, and seven years (69\% v 49\%, p < 0.001) (fig 1, lower panel).

With the Cox multivariate model (table 3), a higher pulmonary wedge pressure, larger left ventricular dimensions, and symptoms of severe heart failure (NYHA class III-IV) predicted mortality or transplantation. Metoprolol showed a significant effect on all cause mortality and combined mortality and transplantation, with respective relative risk reduction values of $51 \%$ (95\% confidence interval -21 to $-69 \%, \mathrm{p}=0.002)$ and $34 \%(-5$ to $-53 \%, \mathrm{p}=0.01)$.

Compared with patients receiving $\leqslant 100 \mathrm{mg}$ metoprolol daily $(n=74)$, those on higher metoprolol doses (>100 mg daily, $\mathrm{n}=98$ ) showed a trend towards a lower incidence of total end points $(17 \% v 30 \%, \mathrm{p}=0.08)$ but not of mortality $(11 \% v 13 \%, \mathrm{p}=0.82)$.

\section{COMPARISON OF MATCHED COHORTS}

One hundred and twenty seven metoprolol treated cases could be matched one to one with controls from the entire cohort on conventional treatment for the variables detailed in Methods. Despite matching, metoprolol treated cases still had a higher cardiac index at haemodynamic evaluation than the controls (table $1 \mathrm{~B})$; on the other hand, they received digitalis more often and amiodarone and loop diuretics less often (table 1A). The great majority of patients from both matched cohorts were treated with ACE inhibitors (94\% v 90\%, NS).

Survival rates at two years $(97 \%$ v $89 \%$, $\mathrm{p}=0.017)$, five years $(84 \% v 72 \%$, $\mathrm{p}=0.0079)$, and seven years $(80 \% v 62 \%$, $\mathrm{p}=0.036$ ) (fig 2, upper panel) were significantly higher in metoprolol treated cases than in matched controls on conventional treatment. The curves were superimposed in the first 12 months after enrolment and then progressively diverged, with differing slopes. Transplant-free survival rates at two years $(90 \%$ v $82 \%, \mathrm{p}=0.055)$, five years $(77 \% v$ $61 \%, p=0.0057)$, and seven years $(68 \% v$ $51 \%, p=0.0053)$ were again significantly 

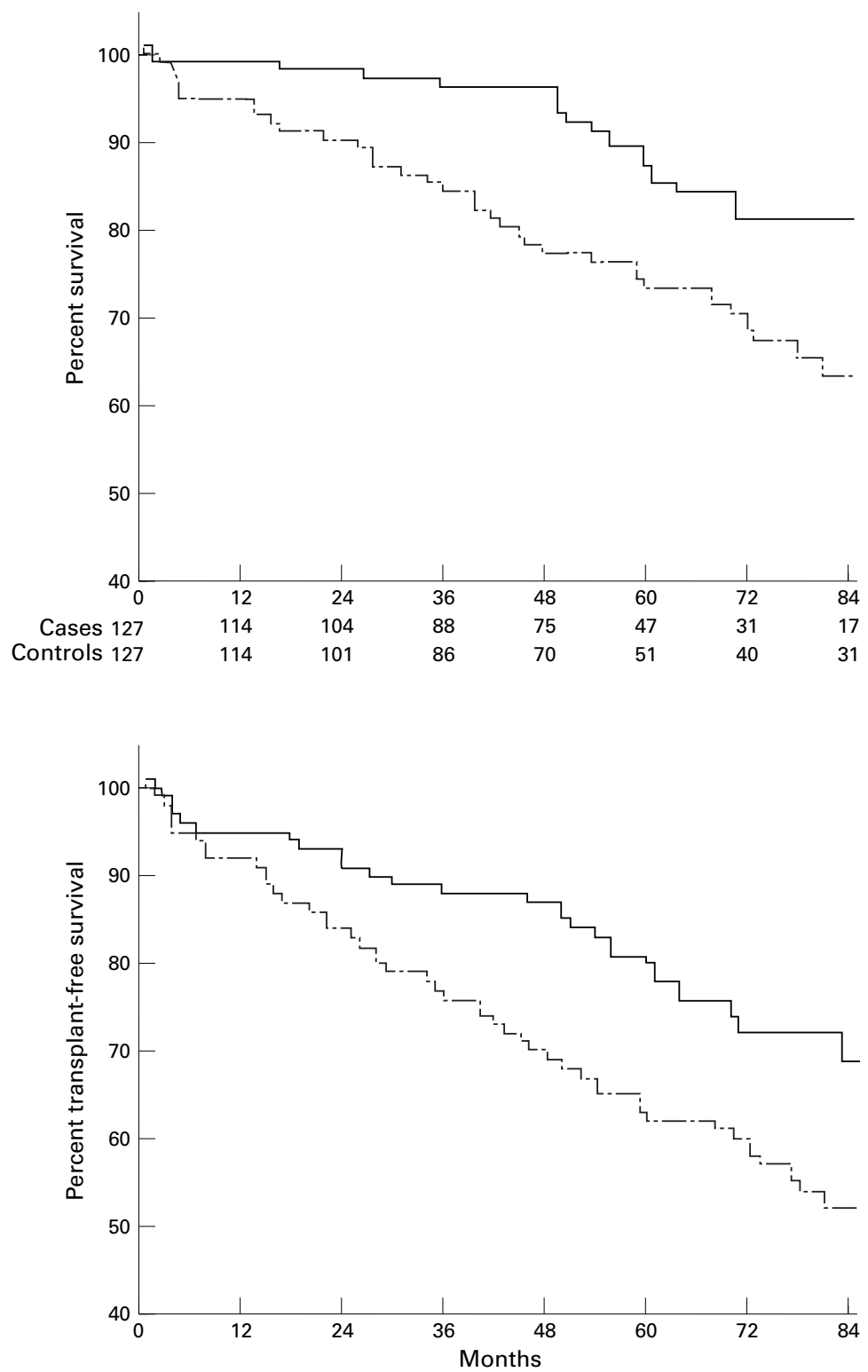

Figure 2 Survival (upper panel) and transplant-free survival (lower panel) in metoprolol treated cases (solid line), and matched control cohort (hatched line). Numbers below the $X$ axis represent patients remaining at risk at each time interval considered.

higher in metoprolol treated cases than in matched controls on conventional treatment (fig 2, lower panel). With the Cox proportional hazards model (table 4), metoprolol treatment was associated with a $30 \%$ reduction in all cause mortality $(95 \%$ confidence interval $-7 \%$ to $-48 \%, \mathrm{p}=0.0147$ ) and a $26 \%$ reduction in mortality or transplantation $(-7 \%$ to $-41 \%$, $\mathrm{p}<0.001)$. A mean aortic pressure decrease of $5 \mathrm{~mm} \mathrm{Hg}$ was associated with an increase in the risk of mortality or transplantation of $11 \%$ ( $1 \%$ to $17 \%, p=0.0047)$; a mean pulmonary artery pressure increase of $5 \mathrm{~mm} \mathrm{Hg}$ was associated with an increase in the risk of mortality or transplantation of $65 \%(52 \%$ to $77 \%$, $\mathrm{p}<0.001)$.

When the competing risk of heart failure death/transplantation or sudden death (table 5) among matched cases and controls was assessed, metoprolol treatment reduced heart failure death/transplantation (relative risk reduction $56 \%, 95 \%$ confidence interval $-9 \%$ to $-79 \%, \mathrm{p}=0.026$ ), but not sudden death (relative risk reduction $41 \%, 95 \%$ confidence interval $-69 \%$ to $13 \%, \mathrm{p}=0.12)$. Amiodarone was not a significant predictor of either type of event, but showed a confounding effect that influenced model stability.

\section{Discussion}

In this retrospective analysis of patients with idiopathic dilated cardiomyopathy enrolled prospectively, the addition of metoprolol to conventional heart failure treatment reduced long term mortality. This survival benefit was confirmed when cases and controls were matched according to baseline disease severity.

Several clinical investigations have already suggested or demonstrated positive clinical responses to chronic treatment with $\beta$ adrenergic blocking drugs in idiopathic dilated cardiomyopathy. ${ }^{6-9}$ Recent randomised trials have also evaluated their efficacy on morbidity and mortality in patients with heart failure. ${ }^{10-12}{ }^{19}$ In the MDC trial, ${ }^{10}$ during a 12 to 18 month follow up, metoprolol treatment was associated with $34 \%$ fewer primary events (death or need for heart transplantation) $(p=0.058)$, a significant reduction in the number of hospital admissions, and a reduced risk of such clinical deterioration as might require cardiac transplantation. In a post hoc analysis, the CIBIS trial ${ }^{11}$ showed a large reduction $(50 \%)$ in mortality with bisoprolol treatment in the subgroup of patients with heart failure and no history of myocardial infarction. More recently, a prematurely terminated multicentre placebo controlled trial ${ }^{12}$ showed that the addition of carvedilol to conventional treatment was associated with a $65 \%$ lower risk of death and a $26 \%$ reduction in hospital admission for cardiovascular causes

Table 3 Cox model of the major independent prognostic determinants in the whole population of patients with dilated cardiomyopathy $(n=586)$

\begin{tabular}{lccccc}
\hline & $\beta$ coefficient & $\begin{array}{l}\text { Robust standard } \\
\text { error }\end{array}$ & $p$ value & Odds ratio & $95 \%$ CI \\
\hline All cause mortality & & & & & \\
LV end diastolic diameter $\left(\mathrm{mm} / \mathrm{m}^{2}\right)$ & 0.0543 & 0.0149 & $<0.001$ & 1.06 & 1.025 to 1.097 \\
Pulmonary wedge pressure $(\mathrm{mm} \mathrm{Hg})$ & 0.0421 & 0.0096 & 0.001 & 1.04 & 1.024 to 1.063 \\
Metoprolol treatment & -0.705 & 0.2391 & 0.002 & 0.49 & 0.309 to 0.789 \\
& & & & \\
Death or transplantation & & & 0.049 & 1.35 & 1.001 to 1.818 \\
NYHA class (III-IV v I-II) & 0.2996 & 0.1522 & $<0.001$ & 1.05 & 1.025 to 1.087 \\
LV end diastolic diameter $\left(\mathrm{mm} / \mathrm{m}^{2}\right)$ & 0.0491 & 0.0124 & $<0.001$ & 1.05 & 1.034 to 1.067 \\
Pulmonary wedge pressure $(\mathrm{mm} \mathrm{Hg})$ & 0.0492 & 0.008 & 0.01 & 0.66 & 0.467 to 0.947 \\
Metoprolol treatment & -0.4087 & 0.1805 & & &
\end{tabular}

LV, left ventricular; NYHA, New York Heart Association. 
among patients with chronic heart failure during an average follow up of 6.5 months. However, these trials have been criticised ${ }^{20}$ on account of inadequacy of sample size,${ }^{10-12}$ relative brevity of follow up, ${ }^{10}{ }^{12}$ and study design. ${ }^{12}$ A recent meta-analysis ${ }^{21}$ of randomised trials of $\beta$ blocker treatment in heart failure, including more than 3000 patients, confirmed a significant reduction in mortality with treatment; however, the maximum follow up did not extend beyond two years.

During the 10 year span of our multicentre registry, we have enrolled a substantial population of patients with invasively documented idiopathic dilated cardiomyopathy and have ensured an adequately long period of follow up. $^{22}$ Patients were generally treated with conventional heart failure drugs, which included ACE inhibitors, but some patients with a left ventricular ejection fraction of less than 0.40 or a history of symptomatic heart failure-mainly from a single centre participating to the MDC trial-were also given metoprolol, up to the maximum tolerated dose. The size of this database and its rigorous selection criteria gave us a unique chance to compare metoprolol treatment with standard treatment, over a follow up period averaging about five years and extending to as long as 10 years. This study is the first to document the efficacy of metoprolol treatment over long term follow up - to our knowledge, controlled data on $\beta$ blockade in heart failure over such an extensive interval have not been reported. ${ }^{10-12} 1923$ The event rate was relatively low, which may be ascribed to the widespread use of current optimal medical treatment for heart failure and to the fact that the study population included many cases in the early stages of the disease. ${ }^{24}$ Despite this paucity of events, the addition of metoprolol in this study had a significant effect on all cause mortality and combined mortality or transplantation.

The survival curves for entire and matched control cohorts were nearly superimposed and differed significantly from the survival curves for the metoprolol cases. The beneficial effects of metoprolol were apparent after six to 12 months of treatment, as reported by previous studies on $\beta$ blockers in heart failure, ${ }^{23}$ which are all consistent with a higher risk of early deterioration with treatment and a delayed effect of $\beta$ blockade on functional indices. ${ }^{5} 101219$ Moreover, the relative risk reduction at two years for combined mortality and transplantation in our study was consistent with the borderline significance of the MDC trial results.

We showed a progressive and sustained improvement in symptoms and cardiac function for up to two years in about $50 \%$ of cases on $\beta$ blocker treatment. ${ }^{70}{ }^{25}$ The progressively divergent slopes of the survival curves after the first months of treatment may represent a reduction in the rate of deterioration and a long term improvement in disease course in metoprolol treated patients in comparison with those on conventional treatment alone.

After extensive stratification for the main indicators of heart failure severity and prognosis, multivariate analysis in the matched population showed a $30 \%$ lower incidence of death with metoprolol and a $26 \%$ reduction in all cause mortality or transplantation. The magnitude of these risk reductions is consistent with the results of previous randomised controlled trials $^{101221}$ : the higher significance observed in this study may be due to the higher incidence of cardiac events during a very long term follow up.

Finally, as in the MDC trial, ${ }^{10}$ improved survival on metoprolol was mainly due to a reduction in heart failure death/transplantation, but not to a significant decrease in sudden death. In the present series amiodarone, though not a significant predictor of survival, had a confounding effect on model stability. The efficacy of amiodarone in heart failure is controversial, although a trend towards treatment induced benefit was shown in non-ischaemic failure ${ }^{26}{ }^{27}$; a beneficial effect of amiodarone in the present series should, however, have diluted and not

Table 4 Cox model of the major independent prognostic determinants of outcome in patients with dilated cardiomyopathy matched for clinical and laboratory findings $(n=254)$

\begin{tabular}{|c|c|c|c|c|c|}
\hline & $\beta$ coefficient & $\begin{array}{l}\text { Robust standard } \\
\text { error }\end{array}$ & $p$ value & $\begin{array}{l}\text { Odds } \\
\text { ratio }\end{array}$ & $95 \% C I$ \\
\hline \multicolumn{6}{|l|}{ All cause mortality } \\
\hline Metoprolol treatment & -0.3596 & 0.1474 & 0.0147 & 0.70 & 0.52 to 0.93 \\
\hline Mean pulmonary artery pressure $(\mathrm{mm} \mathrm{Hg})$ & 0.0552 & 0.0118 & $<0.0001$ & 1.06 & 1.03 to 1.08 \\
\hline \multicolumn{6}{|l|}{ Death or transplantation } \\
\hline Metoprolol treatment & -0.3023 & 0.1161 & 0.0092 & 0.74 & 0.59 to 0.93 \\
\hline Mean pulmonary artery pressure $(\mathrm{mm} \mathrm{Hg})$ & 0.0599 & 0.0094 & $<0.0001$ & 1.061 & 1.04 to 1.08 \\
\hline Mean aortic pressure $(\mathrm{mm} \mathrm{Hg})$ & -0.0216 & 0.0076 & 0.0047 & 0.97 & 0.96 to 0.99 \\
\hline
\end{tabular}

LV, left ventricular; NYHA, New York Heart Association.

Table 5 Cox model of competing risk for sudden death $v$ heart failure death/transplant in patients with dilated cardiomyopathy matched for clinical and laboratory variables $(n=254)$

\begin{tabular}{|c|c|c|c|c|c|}
\hline & $\beta$ coefficient & $\begin{array}{l}\text { Robust standard } \\
\text { error }\end{array}$ & $p$ value & Odds ratio & $95 \% C I$ \\
\hline Constant & 1.056 & & & & \\
\hline Amiodarone $v$ sudden death & 0.1490 & 0.332 & 0.650 & 1.161 & 0.605 to 2.227 \\
\hline \multicolumn{6}{|l|}{ Amiodarone $v$ heart failure } \\
\hline death/transplant & -0.5361 & 0.410 & 0.190 & 0.585 & 0.262 to 1.307 \\
\hline Metoprolol $v$ sudden death & -0.5221 & 0.332 & 0.120 & 0.593 & 0.309 to 1.138 \\
\hline \multicolumn{6}{|l|}{ Metoprolol $v$ heart failure } \\
\hline death/transplant & -0.8278 & 0.372 & 0.026 & 0.437 & 0.211 to 0.906 \\
\hline
\end{tabular}


strengthened the impact of metoprolol on survival.

LIMITATIONS OF THE STUDY

Our investigation has the obvious limitations of an observational cohort study. However, the data analysed were based on a registry where the monitoring and updating were sufficiently continuous to allow the construction of adequate control cohorts. Moreover, the number of patients was not dissimilar from those of previous survival trials on $\beta$ blockers, ${ }^{10-12}$ even if relatively modest compared with the major trials on ACE inhibitors. Nonetheless, our study affords a unique chance-from which randomised placebo controlled trials are inherently precluded - to analyse the effect of metoprolol in idiopathic dilated cardiomyopathy during a long term follow up averaging about five years and extending to as much as 10 years.

Our series is not necessarily representative of heart failure patients in general: all our cases had idiopathic dilated cardiomyopathy, most had mild heart failure, and they were at least one decade younger than patients described in other major trials, ${ }^{11}{ }^{12}$ so caution is mandatory in the extrapolation of the present findings. Moreover, our registry specifically enrolled patients in the early stages of the disease, and selection criteria allowed inclusion of cases with mild depression of left ventricular function. However, in the subgroup of patients with a left ventricular ejection fraction of 0.40 to $0.50,14 \%$ died of cardiac causes and an additional $7 \%$ had heart transplants, a rather substantial value for patients with mild dysfunction, particularly when compared with the $24 \%$ cardiac death and $13 \%$ transplantation rate observed in the cases with more severe impairment of left ventricular function (left ventricular ejection fraction $<0.40$ ), and a finding which raises questions about the apparently benign nature of idiopathic dilated cardiomyopathy in these early stages.

Although treated and untreated cohorts were matched for key prognostic variables, how much of the improvement in survival in metoprolol treated patients was due to differences in other variables that might be related to disease severity cannot be determined. In particular, despite matching, the cardiac index was still significantly higher in metoprolol treated patients, although the clinical relevance of the $0.35 \mathrm{l} / \mathrm{min} / \mathrm{m}^{2}$ average difference may be questioned. However, statistical analysis showed an impressive and highly significant effect of metoprolol treatment on all cause mortality and combined mortality and transplantation, an effect that was "cleansed" of any other clinical or laboratory variables, since those variables that differed in the two cohorts - such as cardiac index-were not significant independent predictors of outcome by multivariate analysis.

We are aware that the confounding effect between metoprolol treatment and the single centre from which the majority of metoprolol treated cases came is unavoidable. This centre effect could influence our results in two different ways: (1) the patients from the single centre might differ in their baseline clinical state from those of the other centres, and (2) the experience and skill of physicians might differ between the centres. We addressed the first point with the matching procedure described in Methods. Unfortunately, the second possibility cannot be estimated. However, we believe this effect to be negligible because all the centres have a long history of scientific and clinical cooperation and thus enjoy a high degree of homogeneity in skills and experience.

CONCLUSIONS

Despite the limitations of an observational cohort study, our investigation supports the hypothesis that metoprolol treatment can modify the long term course of idiopathic dilated cardiomyopathy by causing a sustained decrease in mortality and heart transplantation.

The favourable effects of metoprolol over long term follow up are consistent with the general concept that excessive neuroendocrine activation may be detrimental. ${ }^{34}$ Since the degree of neuroendocrine activation is a strong predictor of mortality, the addition of a $\beta$ receptor blocking agent to optimal conventional drugs may at present provide the best treatment for substantial or symptomatic left ventricular dysfunction in idiopathic dilated cardiomyopathy. Supported by a grant of targeted project FATMA, National
Research Council, Rome, Italy. Dr Gregori was been partly supported during data analysis by Astra GmbH, Germany

\section{Appendix}

Centres participating in the Studio Policentrico Italiano Cardiomiopatie (SPIC)

Milan - Ospedale Niguarda Ca' Granda, Dipartimento di Cardiologia "A De Gasperis": Claudio De Vita, Antonella Moreo, Maurizio Ferratini, Antonio Pezzano, Fabio Recalcati, Edgardo Bonacina;

Florence-Ospedale Careggi, Servizio di Cardiologia San Luca : Alberto Dolara, Mauro Ciaccheri, Gabriele Castelli, Vito Troiani, Franca Gori, Maurizio Nannini; Milan - Ospedale San Carlo, Divisione di Cardiologia: Franco Casazza, Angela Capozzi, Roberto Mattioli; Pisa-Servizio di Cardiostimolazione, Istituto di Fisiologia Clinica del CNR: Andrea Biagini, Oberdan Parodi, Marco Baratto, Danilo Neglia, Gualtiero Pelosi, Annalisa Tongiani, Fabio Vernazza;

Pavia-IRCCS Policlinico San Matteo, Divisione di Cardiologia: Antonello Gavazzi, Carlo Campana, Marina Ponzetta, Eloisa Arbustini, Carlo Montemartini: Trieste-Ospedali Riuniti, Divisione di Cardiologia: Fulvio Camerini, Andrea Di Lenarda, Gerardina Lardieri, Luisa Mestroni, Bruno Pinamonti, Andrea Perkan, Furio Silvestri, Gianfranco Sinagra, Massimo Zecchin, Dario Gregori, Elena Bernobich, Fulvia Longaro, Luca Salvatore, Silvio Klugmann, Milla Davanzo, Cristiana Zanchi;

Varese-Ospedale di Circolo, Divisione di Cardiologia: Giovanni Binaghi, Sergio Repetto, Marcella Luvini; Monza-Ospedale San Gerardo, Divisione e Servizio di Cardiologia: Franco Valagussa, Alessandro Bozzano, Antonio Cadel, Bruno Pria;

Milan-Istituto Villa Marelli, Servizio di Cardiologia: Aldo Sachero, Erminia Giagnoni, Luciano Beretta; Naples-Ospedale Monaldi, Ia Divisione di Medicina: Massimo Cafiero, Massimo Borgia, Franco Costantino, Attilio De Santis, Raffaele D'Oriano;

Vicenza-Ospedale Civile, Divisione di Cardiologia: Mario Vincenzi, Luigi Lavecchia, Renato Ometto; Treviso-Presidio Ospedaliero Multizonale, Divisione di 
Cardiologia: Paolo Stritoni, Giuliano Renosto, Agnese Moro;

Rome-Ospedale San Camillo, Divisione di Cardiologia: Pierluigi Prati, Elisabetta Zachara;

Cagliari-Ospedale Nuovo San Michele, Divisione di Cardiologia: Antonio Sanna, Maurizio Porcu, Stefano Salis, Francesco Uras

\section{Scientific committee}

Giorgio Baroldi, Istituto Fisiologia Clinica del CNR, Sezione di Milano

Fulvio Camerini, Ospedali Riuniti, Divisione di Cardiologia, Trieste

Claudio De Vita, Ospedale Niguarda Cà Granda, Dipartimento di Cardiologia “A. De Gasperis”, Milano

\section{Scientific secreteriat}

Renata De Maria, Istituto Fisiologia Clinica del CNR, Sezione di Milano

Antonello Gavazzi, Divisione di Cardiologia, Policlinico

San Matteo, Pavia

\section{Statistical analysis}

Marina Parolini, Istituto Fisiologia Clinica del CNR, Sezione di Milano

Dario Gregori, Dipartimento di Statistica, Università di Trieste

1 The SOLVD Investigators. Effect of enalapril on survival in patients with reduced left ventricular ejection fraction and congestive heart failure. $\mathrm{N} \mathrm{Engl} \mathrm{f} \mathrm{Med} \mathrm{1991;325:293-302.}$

2 Cohn JN, Johnson GR, Shabetai R, et al. Ejection fraction, peak exercise oxygen erminants of consumption, cardiotpeak exercise oxygen erminants of consumption, cardiothoracic ratio, ventricular arrhythmias, and plasma nore-
pinephrine as determinants of prognosis in heart failure. pinephrine as determinants of progno

3 Swedberg K, Eneroth P, Kjekshus J, et al. Hormones regulating cardiovascular function in patients with severe congestive heart failure and
culation 1990;82:1730-6.

4 Packer M. The neurohormonal hypothesis: a theory to explain the mechanism of disease progression in heart failure. $\mathcal{F}$ Am Coll Cardiol 1992;20:248-54.

5 Ikram H, Fitzpatrick D. Double-blind trial of chronic oral beta-blockade in congestive cardiomyopathy. Lancet 1981, ii: $490-2$.

6 Swedberg K, Hjalmarson A, Waagstein F, et al. Beneficial effects of long term $\beta$ blockade in congestive cardiomyopathy. Br Heart f 1980;44:117-33.

7 Gilbert EM, Anderson JL, Deitchman D, et al. Long-term beta-blocker vasodilator therapy improves cardiac function in idiopathic dilated cardiomyopathy: a double-blind, randomized study of bucindolol versus placebo. $\mathrm{Am} f \mathrm{Med}$ omized study

8 Anderson JL, Gilbert EM, O'Connell JB, et al. Long-term (2 year) beneficial effects of beta-adrenergic blockade with bucindolol in patients with idiopathic dilate

thy. $\mathcal{F}$ Am Coll Cardiol 1991;17:1373-81.
9 Metra M, Nardi M, Giubbini R, Dei Cas L. Effects of shortand long-term carvedilol administration on rest and exercise hemodynamic variables, exercise capacity and linical conditions in patients with idiopathic dilated cardiomyopathy. $7 \mathrm{Am}$ Coll Cardiol 1994;24:1678-87.

10 Waagstein F, Bristow MR, Swedberg K, et al. Beneficial effects of metoprolol in idiopathic dilated cardiomyopathy. Lancet 1993;342:1441-6.

11 CIBIS Investigators and Committees. A randomized trial of $\beta$-blockade in heart failure. The Cardiac Insufficiency Bisoprolol Study (CIBIS). Circulation 1994;90:1765-73.

12 Packer M, Bristow MR, Cohn JN, et al. The effect of carvedilol on morbidity and mortality in patients with chronic heart failure. N Engl f Med 1996;334:1349-55.

$13 \mathrm{WHO} / \mathrm{ISFC}$ task force on the definition and classification of cardiomyopathies. Br Heart F 1980;44:672-3.

14 De Maria R, Gavazzi A, Caroli A, et al. Ventricular arrhythmias in dilated cardiomyopathy as an independent prognostic hallmark. Am 7 Cardiol 1992;69:1451-6.

15 Aretz HT, Billingham ME, Edwards WD, et al. Myocarditis: a histopathologic definition and classification. $A m f$ Cardiovasc Pathol 1987;1:3-14.

16 Pinamonti B, Di Lenarda A, Sinagra G, et al, and the Heart Muscle Disease Study Group. Restrictive left ventricular filling pattern in dilated cardiomyopathy assessed by Doppler echocardiography: clinical, echocardiographic and hemodynamic correlations and prognostic implications. $\mathcal{F}$ Am Coll Cardiol 1993;22:808-15.

17 Rihal CS, Nishimura RA, Hatle LK, et al. Systolic and diastolic dysfunction in patients with clinical diagnosis of sis. Circulation 1994;90:2772-9.

18 Andersen PK, Borgan O. Counting process models for life history data: a review (with discussion). Scand $\mathcal{F}$ Stat 1985; 12:97-158.

18a Lafterty JC. Bivariate survival. Statistical library, 1993. http://lib.stat.cmu.edu

18b Therneau T. Survival4. Statistical library, 1993. http:// lib.stat.cmu.edu

19 Krum H, Sackner-Bernstein JD, Goldsmith RL, et al. Double-blind, placebo controlled study of the long-term efficacy of carvedilol in patients with severe chronic heart failure. Circulation 1995;92:1499-506.

20 Pfeffer MA, Stevenson LW, $\beta$-Adrenergic blockers and survival in heart failure. N Engl f Med 1996;334:1396-7.

21 Heidenreich PA, Lee TT, Massia BM. Effect of betablockade on mortality in patients with heart-failure: a meta-analysis of randomized clinical trials. $\mathcal{F} \mathrm{Am}$ Coll Cardiol 1997;30:27-34.

22 Gavazzi A, De Maria R, Porcu M, et al. Dilated cardiomyopathy: a new natural history? $G$ Ital Cardiol 1995;25:1109-25.

23 Doughty RN, MacMahon S, Sharpe N. Beta-blockers in heart failure: promising or proved? f Am Coll Cardiol 1994; 23:814-21.

24 Di Lenarda A, Secoli G, Perkan A, et al. Changing mortality in dilated cardiomyopathy. Br Heart $\mathcal{F}$ 1994;72(suppl): S46-51

25 Di Lenarda A, Gregori D, Sinagra G, et al. Metoprolol in dilated cardiomyopathy: it is possible to identify factors predictive of improvement? f Cardiac Failure 1996;2:87102.

26 Doval HC, Nul DR, Perrone SV, et al, for Grupo de Estudio de la Sobrevida en la Insufficiencia Cardiaca en Argentina (GESICA). Randomised trial of low-dose amiodarone in severe congestive heart failure. Lancet 1994;344:493-8.

27 Singh SN, Fletcher RD, Gross Fisher S, et al. Amiodarone in patients with congestive heart failure and asymptomatic ventricular arrhythmia. $N$ Engl f Med 1995;333:77-82. 